\title{
A New NO-Releasing Nanoformulation for the Treatment of Pulmonary Arterial Hypertension
}

\author{
Nura A. Mohamed ${ }^{1,2,3} \cdot$ Blerina Ahmetaj-Shala $^{1}$ Lucie Duluc $^{4} \cdot$ Louise S. Mackenzie $^{5}$. \\ Nicholas S. Kirkby ${ }^{1}$ - Daniel M. Reed ${ }^{1} \cdot$ Paul D. Lickiss ${ }^{6} \cdot$ Robert P. Davies $^{6}$. \\ Gemma R. Freeman ${ }^{6}$ Beata Wojciak-Stothard ${ }^{4}$ - Adrian H. Chester ${ }^{2}$. \\ Ibrahim M. El-Sherbiny ${ }^{7}$. Jane A. Mitchell ${ }^{1}$ - Magdi H. Yacoub ${ }^{2}$ \\ Received: 10 February 2016 / Accepted: 17 February 2016/Published online: 9 March 2016 \\ (C) The Author(s) 2016. This article is published with open access at Springerlink.com
}

\begin{abstract}
Pulmonary arterial hypertension (PAH) is a chronic and progressive disease which continues to carry an unacceptably high mortality and morbidity. The nitric oxide (NO) pathway has been implicated in the pathophysiology and progression of the disease. Its extremely short half-life and systemic effects have hampered the clinical use of NO in PAH. In an attempt to circumvent these major limitations, we have developed a new NO-nanomedicine formulation. The formulation was based on hydrogel-like polymeric composite NO-releasing nanoparticles (NO-RP). The kinetics of NO release from the NO-RP showed a peak at about 120 min followed by a sustained release for over $8 \mathrm{~h}$. The NO-RP did not affect the viability or inflammation responses of endothelial cells. The NO-RP produced concentration-dependent relaxations of pulmonary arteries in mice with PAH induced by hypoxia. In conclusion, NO-RP drugs could considerably enhance the therapeutic potential of NO therapy for PAH.
\end{abstract}

Keywords Pulmonary arterial hypertension $\cdot$ Nanomedicine Nanoparticles $\cdot$ Nitric oxide $\cdot$ NO-releasing nanoparticles ·

\section{Associate Editor Daniel P. Judge oversaw the review of this article}

Nura A. Mohamed and Blerina Ahmetaj-Shala contributed equally and share first author

Adrian H. Chester, Ibrahim M. El-Sherbiny, Jane A. Mitchell and Magdi H. Yacoub contributed equally, share senior authorship and their names appear in alphabetical order.

Magdi H. Yacoub

m.yacoub@imperial.ac.uk

1 Department of Cardiothoracic Pharmacology, National Heart and Lung Institute, Imperial College, Dovehouse Street, London SW3 6LY, UK

2 Heart Science Centre, Imperial College, Harefield, Uxbridge UB9 $6 \mathrm{JH}, \mathrm{UK}$

3 Qatar Foundation Research and Development Division, Doha, Qatar
Endothelial cells $\cdot$ Pulmonary artery vascular smooth muscle cells $\cdot$ Pulmonary artery $\cdot$ Aorta

Pulmonary arterial hypertension (PAH) continues to carry very poor prognosis in terms of both survival and quality of life in spite of the use of modern combination therapy [1]. This could be, at least in part, due to the fact that the exact molecular mechanisms remain largely unknown. The pathophysiology of the disease includes pulmonary vasospasm, vascular remodeling, and right ventricular failure. Several pathways have been implicated in the pathophysiology of PAH [2]. This has stimulated development of agents that can influence these pathways. One of the most promising strategies is modulating the nitric oxide (NO) pathway due to the apparent central role of NO in this disease [3]. NO is a potent vasodilator with anti-proliferative and anti-coagulant effects [3]. Several attempts at using inhaled NO gas in humans with both acute and chronic PAH have been tried [4]. The effect of NO gas is grossly limited by its short half-life and metabolism of cGMP by phosphodiesterase (type I and V) enzymes. In

4 Department of Experimental Medicine and Toxicology, Hammersmith Campus, Imperial College London, Du Cane Road, London W12 0NN, UK

5 School of Life and Medical Sciences, University of Hertfordshire, Hatfield AL10 9AB, UK

6 Synthesis Section, Department of Chemistry, Imperial College London, South Kensington, London SW7 2AZ, UK

7 Center for Materials Science, Zewail City, Sheikh, Zayed District, 12588, 6th of October City, Giza, Egypt 
addition, adverse effects limit the systemic use of NO donors. Some of these limitations could be overcome by inhalation therapy particularly if combined with the use of a slow release nanoparticle formulation. There are several types of particles that may be useful as carriers of NO for the treatment of PAH including polymeric carriers [5]. Polymers have the advantage as potential drug carriers because they are biocompatible and their surface can be readily modified [5].

In an attempt to circumvent these major limitations, we have developed and performed extensive preclinical testing of a new NO-nanomedicine formulation. The NOreleasing polymers (NO-RPs) were prepared via ionotropic gelation technique. In brief, acidic solution of methyl silicate $(2.8 \mathrm{ml} / \mathrm{ml})$ was sonicated in ice bath at a power of $45 \mathrm{~kW}$ with $10 \mathrm{~s}$ pulse on and $5 \mathrm{~s}$ pulse off, followed by adding $1.1 \mathrm{ml}$ of oligochitosan solution $(0.5 \% w / v, 15 \mathrm{KDa})$, polyvinylpyrrolidone $(6.25 \mathrm{mg}$, $40 \mathrm{kDa})$, and $2.1 \mathrm{ml}$ of polyethylene glycol $(0.4 \mathrm{kDa})$ with stirring for $5 \mathrm{~min}$. Afterwards, $15 \mathrm{ml}$ of nitrite solution $(3 \% w / v)$ containing a predetermined weight of reducing agent was added followed by dropwise addition of $5 \mathrm{ml}$ aqueous sodium tripolyphosphate $(0.08 \% \mathrm{w} / \mathrm{v})$ with stirring. The resulting mixture was left at ambient temperature for $30 \mathrm{~min}$ followed by freeze-drying. The NO-RPs were characterized using Fourier transform infrared, X-ray diffraction, differential scanning calorimetry, scanning electron microscopy (SEM) and highresolution transmission electron microscopy (HR-TEM). The particle size, as determined by dynamic light scattering, was in the range of $200-230 \mathrm{~nm}$. This size was also confirmed using SEM and HR-TEM, which demonstrated a fine structure of the NO-RPs particles with a non-spherical morphology (Fig. 1a).

In aqueous solution, simulating in vivo conditions, the NO-RP released NO in a concentration dependent manner with steady-state kinetics noted at $6.6 \mathrm{~min}$ (Fig. 1b) compared to NO release by SNP which was 6-times higher than the NO-RP at the same time point. When measured up to $8 \mathrm{~h}$, NO release from the NORPs at a concentration of $5 \mathrm{mg} / \mathrm{ml}$ revealed two phases with an early peak lasting approximately $120 \mathrm{~min}$ followed by a decline (approximately $50 \%$ ) and a new steady state lasting for at least $8 \mathrm{~h}$ (Fig. 1c). When hemoglobin was added to the reaction mixture containing either NPs or SNP, NO release (measured by an NO-electrode) was quenched, confirming that free NO, rather than a higher oxide, was being detected. a

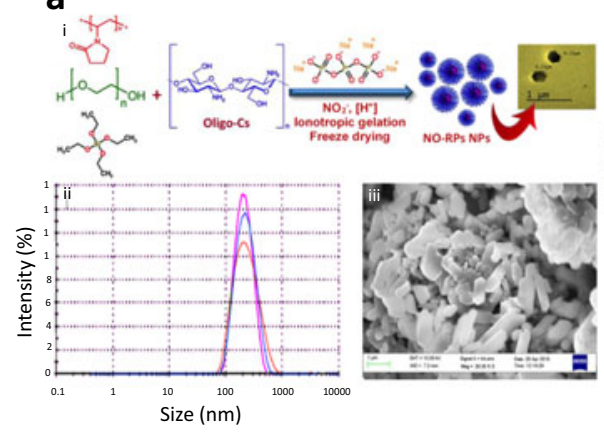

C

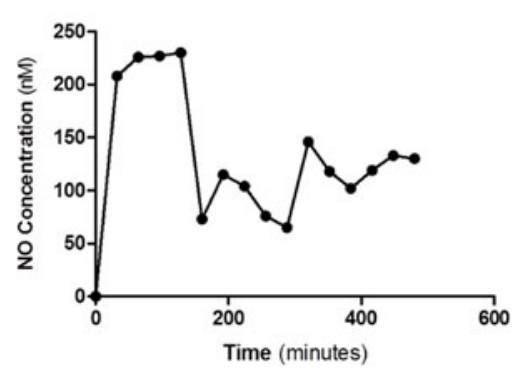

Fig. 1 a (i) A schematic illustration of the development of the NOreleasing polymer and transmission electron microscopy image of the particles, size and morphology of the NO-releasing polymers as determined by (ii) dynamic light scattering and (iii) scanning electron microscopy at $\times 3035$. b NO release from different concentrations of NO-releasing polymers (NO-RPs). Measurements were recorded using NO measuring electrode over a period of $20 \mathrm{~min}$. c NO release b

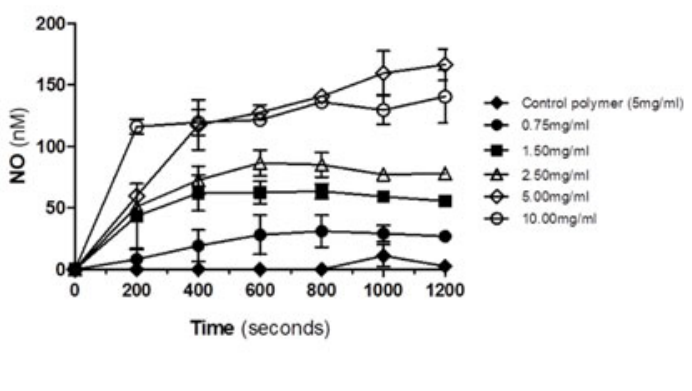

d

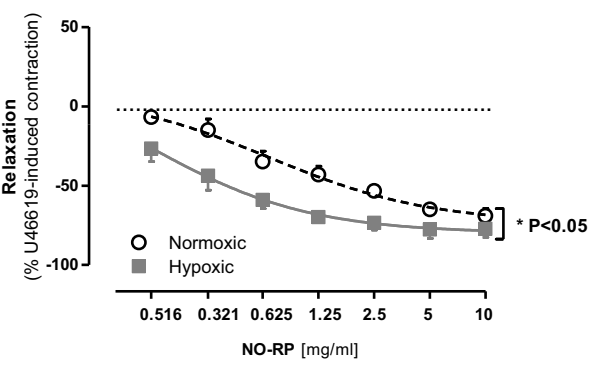

pharmacokinetics from the NO-releasing polymers (NO-RPs). Measurements were recorded using NO measuring electrode over a period of $8 \mathrm{~h}$. d Effect of NO-releasing polymer (NO-RP) on precontracted pulmonary artery from control mice and mice with pulmonary arterial hypertension. Data represents mean \pm SEM for $n=3$ from three animals. Statistical significance was determined by two-way ANOVA followed by a Bonferroni post hoc test $\left({ }^{*} p<0.05\right)$ 
At concentrations up $10 \mathrm{mg} / \mathrm{ml}$ both control and the NORPs showed no effect on viability of endothelial cells under control culture conditions or in experiments where LPS was added to induce inflammation. Similarly, NO-RPs had no effect on basal or LPS-induced CXCL8 release from endothelial cells. The NO-RPs demonstrated no effect on pulmonary artery smooth muscle cell viability.

NO-RPs induced concentration-dependent relaxations of both aorta and pulmonary arteries (Fig. 1d). It was interesting to note that the NO-RPs appeared selective for vessels from mice with pulmonary hypertension displaying an increased $\mathrm{EC}_{50}$ compared to pulmonary arteries from control mice. SNP similarly induced vasodilator responses in pulmonary artery from both control mice and mice with pulmonary hypertension.

The current findings are essentially preliminary in nature and these findings need to be investigated further with additional experiments. In vivo studies with NO-RPs are required as there is a need to establish a clear benefit over existing therapeutic strategies in use of these molecules in the treatment of PAH.

These observations do show that NO-RPs (i) release free NO in aqueous solution, (ii) are non-toxic to cells and (iii) relax systemic (aorta) and pulmonary vessels. Our findings that this novel class of molecules appeared to selectively target vessels from mice with pulmonary hypertension is interesting and supports the idea that these preparations may be useful in the treatment of human disease.

Acknowledgments Nura A Mohamed is a recipient of a Qatar Foundation scholarship. This project was supported by the NIHR Respiratory Disease Biomedical Research Unit at the Royal Brompton and Harefield NHS Foundation Trust, Imperial
College London and the Magdi Yacoub Institute. The views expressed in this publication are those of the authors(s) and not necessarily those of the NHS, The National Institute for Health Research or the Department of Health.

\section{Compliance with Ethical Standards}

Source of Funding This work was supported by funds from the Qatar Foundation for research and human development $(\mathrm{QF})$ and the Magdi Yacoub Institute (MYI).

Open Access This article is distributed under the terms of the Creative Commons Attribution 4.0 International License (http:// creativecommons.org/licenses/by/4.0/), which permits unrestricted use, distribution, and reproduction in any medium, provided you give appropriate credit to the original author(s) and the source, provide a link to the Creative Commons license, and indicate if changes were made.

\section{References}

1. Ghofrani, H. A., \& Humbert, M. (2014). The role of combination therapy in managing pulmonary arterial hypertension. European Respiratory Review, 23(134), 469-475.

2. Archer, S. L., Weir, E. K., \& Wilkins, M. R. (2010). Basic science of pulmonary arterial hypertension for clinicians: new concepts and experimental therapies. Circulation, 121(18), 2045-2066.

3. Tonelli, A. R., Haserodt, S., Aytekin, M., \& Dweik, R. A. (2013). Nitric oxide deficiency in pulmonary hypertension: pathobiology and implications for therapy. Pulmonary Circulation, 3(1), 20-30.

4. Barst, R. J., Channick, R., Ivy, D., \& Goldstein, B. (2012). Clinical perspectives with long-term pulsed inhaled nitric oxide for the treatment of pulmonary arterial hypertension. Pulmonary Circulation, 2(2), 139-147.

5. El-Sherbiny, I. M., El-Baz, N. M., \& Yacoub, M. H. (2015). Inhaled nano- and microparticles for drug delivery. Global Cardiology Science \& Practice, 2015, 2. 